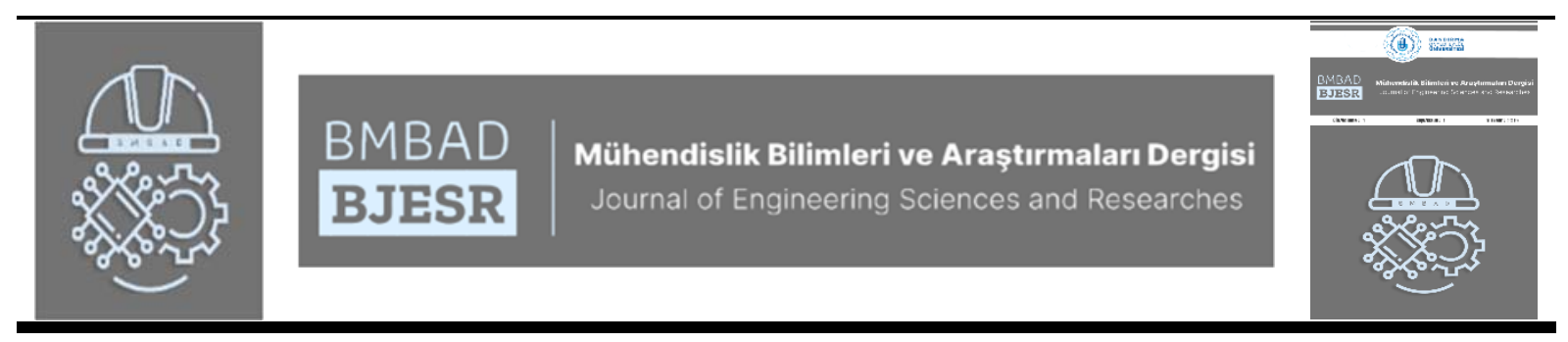

\title{
Kalsit Mineral Katkılı Orta Yoğunlukta Liflevha (MDF)'nin Yanma Performansının Araştırılması
}

\section{Investigation of Combustion Performance of Calcite Mineral Added Medium Density Fiberboard (MDF)}

\author{
${ }^{1}$ Osman ÇAMLIBEL (D) , ${ }^{2}$ Mehmet AKGÜL \\ ${ }^{1}$ Kırıkkale Üniversitesi, Kırıkkale Meslek Yüksekokulu, İ̧ Mekan Tasarım, Kırıkkale, Türkiye \\ ${ }^{2}$ Karamanoglu Mehmetbey Üniversitesi, Karaman, Türkiye \\ ${ }^{1}$ osmancamlibel@kku.edu.tr. ${ }^{2}$ mehmetakgul@kmu.edu.tr \\ Araştırma Makalesi/Research Article
}

\begin{tabular}{l}
\hline A R T I C L E I N F O \\
Article history \\
Received :13 December 2020 \\
Accepted : 30 December 2020
\end{tabular}

Keywords:

MDF,Combustion, Calcite,Inorganic Mineral, Fire Resistance

A B S T R A C T

In this study, in order to increase the fire resistance properties of MDF boards, the possibilities of using calcite mineral in MDF production were investigated. Wood chips were cooked for 4 minutes at 7.5 bar, and $180^{\circ} \mathrm{C}$ temperature in an Asplund defibrator. Instead of lignocellulosic fibers used for the manufacture $1 \mathrm{~m}^{3} \mathrm{MDF}$, liquid paraffin before fibrillation, then hardener, resin and calcite mix solutions were added on fibers as 3\%, 6\%, 9\% according to total amount of fibers in blowline, respectively. The fibers were dried to $12 \%$ moisture by the dryer. Boards were produced $185^{\circ} \mathrm{C}$ temperature, $32 \mathrm{~kg} / \mathrm{cm}^{2}$ pressure and 270 second pressing time by multi-day eight-layer hot press. Boards were sanded by 50, 80 and 120 grit size sanding belts. Combustion tests of MDFs' were carried out FIC, SC, ESC, FIC lux, SC lux, ESC lux, IST, ESCS and weight loss. Consequently, calcite minerals have increased the resistance to fire of MDF as good performance.

(C) 2020 Bandirma Onyedi Eylul University, Faculty of Engineering and Natural Science. Published by Dergi Park. All rights reserved.

Makale Tarihleri

Gönderim : 13 Aralık 2020

Kabul : 30 Aralık 2020

Anahtar Kelimeler:

MDF, Yanma, Kalsit, İnorganik Mineral, Yanma Direnci

\section{Ö Z E T}

Bu çalışmada, MDF levhaların yangına dayanıklılık özelliklerini arttırmak için kalsit mineralinin MDF üretiminde kullanılma imkanları araştırılmıştır. Yongalar Asplund defibratörde 4 dakika 7.5 bar ve $180^{\circ} \mathrm{C}$ sicaklıkta pişirilmiştir. Liflendirmeden önce \% 1,5 sıvı parafin mantarlaşmış yongalara verilmiştir. $1 \mathrm{~m}^{3} \mathrm{MDF}$ üretimi için kullanılan lignoselülozik liflerin yerine; $\% 3, \% 6, \% 9$ oranlarında kalsit minerali üre formaldehite tutkalı ve sertleştirici ile karıştırılarak blowlinedan liflere verilmiştir. Lifler \% 12 rutubete kadar kurutulmuştur. Levhalar $185^{\circ} \mathrm{C}$ sıcaklık, $32 \mathrm{~kg} / \mathrm{cm}^{2}$ basınç ve 270 saniyede sekiz katlı sicak preste preslenmiştir. Üretilen levhalar 50, 80 ve 120 tane büyüklüğünde zımpara bantları ile zımparalanmıştır. Kalsit katkılı üretilen levhaların yanma testleri; AKY, KKY, KHY, AKY lüks, KKY lüks, KHY lüks, IYYB, KHYS, Ağırlık kaybı deneyleri yapılmıştır. Sonuç olarak kalsit mineralleri; levhaların yangına karşı direnç testinde iyi bir performans gösterdiği belirlenmiştir.

(C) 2020 Bandırma Onyedi Eylül Üniversitesi, Mühendislik ve Dağa Bilimleri Fakültesi. Dergi Park tarafından yayınlanmaktadır. Tüm Hakları Saklıdır. 


\section{GÍRIŞ}

Lif levha (MDF) üretiminde yongalara veya selülozik liflere uygun oranlarda inorganik malzemeler ve türevi materyaller karıştırılarak ve kimyasalların ilavesiyle düzgün yüzeyli paneller üretilebilmektedir.

İnorganik kaya tuzunun MDF üretiminde kullanılabilirliğini araştırmışlardır. Çalışmalarında, Kaya tuzu katkılı MDF levhalarının fiziksel, mekanik ve yanma performanslarını araștırmışlardır [20].

MDF üretiminde, melamin üre formaldehit (MUF) içeriklerine bazı bor bileşiklerini (\%10, \%15, \%20) oranında ekleyerek levhaların üretimini gerçekleştirmişlerdir. Çalışmalarında, özellikler bor bileşiklerinin levhaların fiziksel ve mekanik etkisini incelemişlerdir. Reçine içinde melamin içeriği artıkça levhaların bazı özelliklerini pozotif yönde etkilediğini ifade etmişlerdir. [6].

Çimento kompozitleri ve odun yünü üzerine bazı çalışmalar yapmışlardır [10].

Vermikülit katkıı MDF levhalar üretmişlerdir. Araştırmalarında levhaların özelliklerini, oksijen endeksinin sınırlandırılmasını (LOI), eşzamanlı termal analizi (TG-DSC), eğilme direnci (MOR) ve elastikiyet modülünü (MOE) araştırmışlardır [12].

Agresif lignoselülozik biyokütle (bamya, tütün, findık, ceviz cehennemi, çam kozalağı) kombinasyonlarıyla orta yoğunlukta lif levha (MDF) üretmişlerdir. Araştırmalarında, üretilen orta yoğunluklu lif levhanın (MDF) fiziksel ve mekanik özelliklerini araştırmışlardır [13].

Di-amonyum fosfat, mono amonyum fosfat, çinko klorür, amonyum sülfat, boraks ve borik asit gibi inorganik tuzları Güney çamın hammadde olarak ve bu türden üretilen kontrplaklarda kullanmışlar ve yanma derecelerini test ederek kimyasalların alev geciktirici olarak performanslarını araştırmışlardır [15].

Mikrokristalin selüloz termoplastik kompozitler için alev geciktiriciler olarak amonyum zeolit ve amonyum fosfatı araştırmışlardır [3].

Yangın geciktiricilerin su, bağlayıcı, kalsit ve çeşitli alev geciktiricilerle kombine edilmiş kaplamaları ile kaplanmış orta yoğunluklu lif levhaların yanma performansı özelliklerini araştırmışlardır [2].

Bazı yangın geciktiricilerle işlenmiş kayın (Fagus orientalis L.) kaplamalardan hazırlanan lamine kaplama kerestenin (LVL) yanma özelliklerini incelemiştir. Çalışmalarına göre, en düşük sıcaklık ve kütle kaybı, diamonyum fosfat ve borik asit-boraks karışımı ile muamele edilen numunelerde elde etmişlerdir [4].

Ahşap yapılar için yangın geciktirici olarak disodyum oktaborat tetrahidrat bazlı ve tanin-bor bazlı formülasyonlarının karşılaştırmalarını incelemişlerdir. Ahşap panellerde yangın geciktiricilerin oranı artırıldığında yangın performanslarının daha da arttığını ifade etmişlerdir [8].

Saman-magnezyum çimento (SMC) kompozitlerinin su direncini, yangın geciktirici performanslarını ve mekanik mukavemetini iyileştirmek için çalışmışlardır [17].

MDF ve kontrplak panellerin üretiminde çeşitli yangın geciktiricileri kullanarak ve üretilen levhaların yanma performansına etkileri belirlemişlerdir. Araştırma sonucunda; MDF ve kontrplağın yangın performansının yaklaşık $\% 6,4$ ve $\% 1,6$ arttığını göstermişlerdir [9].

Laboratuvar ortamında öğütülmüş kalsiyum karbonat (GCC) dolgu ilaveli $8 \mathrm{~mm}$ kalınlığında MDF levhalar imal etmişlerdir. MDF'ler ağırlık bazında (kuru/kuru) sırasıyla 550,700 ve $850 \mathrm{~kg} / \mathrm{m}^{3}$ hedef yoğunluklarda $\% 10, \% 20$ ve \%30 oranlarında kalsiyum karbonat katkılı levhalar üretmişlerdir. Ancak MDF'nin ağaç lifi yerine ağırlıkça $\% 10$ 'dan fazla öğütülmüş kalsiyum karbonat içerdiği, levhaların fiziksel ve mekanik özelliklerini çok olumsuz etkilendiğini bildirilmişlerdir [16].

$\mathrm{MDF}$ üretiminde $\mathrm{ZnO}$ nano-partiküllerinin $\% 0.5$ ve $\% 1.0$ oranında üre formaldehit reçinesi ve melamin formaldehit reçinesi ile birleştirerek levhalar üretmişlerdir. Araştırmalarında $\mathrm{ZnO}$ nanopartiküllerinin levhaların fiziksel özelliklerine etkisi, nemli ortamlarda levhaların kullanılması nedeniyle dirençlerinin tespiti ve mantar saldırılarına karşı mukavemet değerleri üzerine çalışmışlardır [5].

MDF'yi wollastonit (kalsiyum inosilikate mineral) elyaflarından ile deve dikeni ağaç liflerinin karışımıyla levhalar üretmişlerdir. Bu levhaların fiziksel ve mekanik özelliklerini araştırmışlardır [11].

Özellikle iç mekân mutfak mobilyaları ve otellerin mutfak mobilyalarında yangına dirençli levhalara ihtiyaç artmaktadır. Mutfak mobilya üretiminde kullanılan MDF'ler yangın geciktirici özellik kazandırılmalıdır. Ülkemizde veya Dünyada toplam MDF üretimi içinde yangına dirençli levhaların oranı artırılmalıdır. 2018 yılında, Türkiye'de MDF/HDF üretimi $4.910 .000 \mathrm{~m}^{3} / \mathrm{y} 1 \mathrm{l}$, Avrupa da MDF üretimi yaklaşı $17.764 .338 \mathrm{~m}^{3} / \mathrm{y} 1 \mathrm{l}$ ve Dünyada 99.443.242 m3/y1l üretim gerçekleşmiştir [7].

Yangına dirençli levhalar, mutfak mobilyalarında kullanımı artıkca, yaşam alanlarında yangın çıkma riskini minimize edebilecektir.

Bu çalışma; lignoselülozik hammaddeler yerine kalsit (\%3, \%6, \%9) minerallerinin kullanımıyla MDF levhaları üretim prosesinde üretilmiştir. Üretilen kontrol levhası ve kalsit mineral katkılı levhaların yangına karşı mukavemet seviyelerinin araştırılması amacıyla deneysel araştırmalar yapılmıştır. 


\section{MATERYAL VE YÖNTEM}

\subsection{Malzeme}

\subsubsection{MDF üretiminde kullanılan odun hammaddeler}

MDF üretiminde kullanılan odun materyali; Kayın (Fagus Orientalis L.) odunları Düzce ili Orman Bölge işletmelerinden, Meşe (Quercus Robur L) odunları Batı Karadeniz bölgesinden ve Çam (Pinus sylvestris L) odunları Bolu ilinden tedarik edilmiştir.

\subsubsection{Kalsit $\left(\mathrm{CaCO}_{3}\right)$}

Kalsit inorganik minerali $2.5-2.7 \mathrm{~g} / \mathrm{cm}^{3}$ sertliğinde ve özgül ağırlı̆̆ı ile $\% 90 \mathrm{CaCO}_{3}$ içeren kalkerden oluşur. Kalsiyum oksit, su ile reaksiyona girerek kalsiyum hidroksite dönüştürülür. Aksaray ili civarından kalsit malzemeleri temin edildi.

\subsubsection{Kimyasallar}

Üre formaldehit reçineleri, sıvı parafin ve amonyum sülfat sırasıyla Gebze Polisan firmasından, Denizli Mercan Kimyadan ve Gebze'den özel bir firmadan temin edildi. Kimyasalların spesifik değerleri çizelge 1'de gösterilmiştir.

Çizelge 1. MDF üretiminde kullanılan kimyasalların spesifik değerleri.

\begin{tabular}{|c|c|c|}
\hline Sira no & Ürün özellikleri & Ölçüm değeri \\
\hline Tutkal & Görünüş & Temiz, beyaz sıvı \\
\hline (Poliüre & Katı madde \% & $65 \pm 1$ \\
\hline \multirow[t]{9}{*}{ 2265) } & Formaldehit/üre mol oranı & 1.22 \\
\hline & Yoğunluk $\left(20^{\circ} \mathrm{C} \mathrm{gr} / \mathrm{cm}^{3}\right)$ & 1.227 \\
\hline & Vizkosite $\left(20^{\circ} \mathrm{C} \mathrm{cps}\right)$ & 185 \\
\hline & $\operatorname{Akma}$ zaman $1\left(20^{\circ} \mathrm{C}, \mathrm{FC} 4, \mathrm{sn}\right)$ & $25-40$ \\
\hline & Jelleşme zaman $1\left(100^{\circ} \mathrm{C}, \mathrm{sn}\right)\left(\%\right.$ 10luk $\left.\left(\mathrm{NH}_{4}\right)_{2} \mathrm{SO}_{4}\right)$ & $40-60$ \\
\hline & $\mathrm{pH}$ & $7.5-8.5$ \\
\hline & Serbest formaldehit miktarı \% & 0.5 maksimum \\
\hline & Metilol grupları \% & $12-15$ \\
\hline & Depolama zaman $1\left(20^{\circ} \mathrm{C}\right.$, gün $)$ & 45 \\
\hline \multirow{4}{*}{$\begin{array}{l}\text { Siv1 } \\
\text { parafin }\end{array}$} & Görünüş & Krem, light \\
\hline & Erime noktası & Siv1 \\
\hline & Yağ oran1 \% & 2 maksimum \\
\hline & Penetrasyon & 32 \\
\hline \multirow{2}{*}{$\begin{array}{l}\text { Amonyum } \\
\text { sülfat }\end{array}$} & Görünüş & Kirli beyaz \\
\hline & Yap1 & Kristal taneli \\
\hline
\end{tabular}

\subsection{METOT}

\subsection{1. Üretim reçetelerinin oluşturulması}

İnorganik dolgu mineral katkılı solüsyon karışımının lignoselülozik materyallere karıştırılmasıyla oluşturulacak üretim reçetesi, çizelge 2 'de verilmiştir.

Çizelge 2. Üretim parametreleri ve presleme şartları

\begin{tabular}{|c|c|c|c|c|c|c|c|c|c|c|c|}
\hline \multicolumn{12}{|c|}{ Üretim parametreleri ve presleme şartları } \\
\hline $\begin{array}{l}\text { Levha } \\
\text { grubları }\end{array}$ & $\begin{array}{l}\text { Lif } \\
(\%)\end{array}$ & $\begin{array}{c}\text { Kalsit } \\
\text { mineraller } \\
(\%)\end{array}$ & $\begin{array}{c}\text { Reçine } \\
\text { (ÜF) } \\
(\%)\end{array}$ & $\begin{array}{l}\text { Sertleştirici } \\
\text { (AS) } \\
(\% 20)\end{array}$ & $\begin{array}{c}\text { Sivı } \\
\text { Waks } \\
(\%)\end{array}$ & $\begin{array}{l}\text { Lif } \\
\text { rutubeti } \\
(\%)\end{array}$ & $\begin{array}{c}\text { Pres } \\
\text { Sicaklığ } 1 \\
\left({ }^{\circ} \mathrm{C}\right)\end{array}$ & $\begin{array}{l}\text { Pres basinc1 } \\
\left(\mathrm{Kg} / \mathrm{cm}^{2}\right)\end{array}$ & $\begin{array}{l}\text { Pres } \\
\text { süresi } \\
(\mathrm{dk})\end{array}$ & $\begin{array}{c}\text { Zımparalı } \\
\text { levha } \\
\text { kalınlığ } \\
(\mathrm{mm})\end{array}$ & $\begin{array}{l}\text { Levha } \\
\text { rutubeti } \\
(\%)\end{array}$ \\
\hline Kontrol & 100 & 0 & 11.5 & 1 & 1.5 & 12 & $185-190$ & $32-34$ & 4.50 & 18 & 7.50 \\
\hline $\mathrm{R}_{97} \mathrm{C}_{3}$ & 97 & 3 & 11.5 & 1 & 1.5 & 12 & $185-190$ & $32-34$ & 4.50 & 18 & 7.89 \\
\hline $\mathrm{R}_{94} \mathrm{C}_{6}$ & 94 & 6 & 11.5 & 1 & 1.5 & 12 & $185-190$ & $32-34$ & 4.50 & 18 & 7.20 \\
\hline $\mathrm{R}_{91} \mathrm{C}_{9}$ & 91 & 9 & 11.5 & 1 & 1.5 & 12 & $185-190$ & $32-34$ & 4.50 & 18 & 7.50 \\
\hline
\end{tabular}

R: $1 \mathrm{~m}^{3}$ levha için tüketilen (ibreli+ibresiz) odun, C: $1 \mathrm{~m}^{3}$ levha için tüketilen kalsit minerali, $\mathrm{R}_{\mathrm{x}} \mathrm{C}_{\mathrm{y}}$ : yüzdelik (\%) karışım, ÜF: Üre formaldehit, AS: Amonyum sülfat ve Waks: Parafin. 


\subsubsection{MDF levhalarının üretilmesi}

Kalsit katkılı deneme levhalar, Düzce ilinde bulunan Divapan Entegre AŞ firmasnını MDF üretim hattında üretilmiştir. Üretim esnasında diğer üretim parametreleri sabit kalmış ve sadece kalsit inorganik mineral karışım oranları değiştirilerek üretimi gerçekleşen genel amaçlı levhalardır. Deneme levhalarına çizelge 2'deki üretim parametreleri uygulanmıştır. MDF levhalarının üretiminde orman işletme depolarından tedarik edilen kayın, saplı meşe ve çam odunu hammadde olarak kullanılmıştır. Odunlar yongalayıcıda yonga haline getirilmiştir. Yongalar yonga depolama silolarında stoklanmıştır. Siloların çıkışında yonga karışım oranları belirlenmiştir. Yongalar mekanik elekte elenmiștir.

Rafinör ünitesinde yongalar $180^{\circ} \mathrm{C}$ ve 7.5 bar buhar basıncında 4 dakika buhar ile pişirilerek mantarlaştırılmıştır. Mantarlaşan yongalara liflendirmeden önce sıvı parafin verilmiştir. Yongalar defibrator segmentlerinde lif haline getirilmiştir. Defibrator çıkışı ve blowline bölümünde liflere sertleştirici (amonyum sülfat) (\%20) solüsyonu eklenmiştir. Kalsit mineralleri ayrı bir tankta \%50 solüsyon halinde hazırlandı ve rezerv tankına alındı. Tankların altında karıştırıcı ile solüsyon sürekli karıştırılmıştır. Çizelge 2'deki parametrelere göre üre formaldehit tutkalı ile karıştırılarak sevk pompası ile blowline liflere eklenmiştir. Kimyasallar ve kalsit eklenen lifler kurutucuda \%12 rutubete kadar kurutulmuştur.

Kurutulan lifler mekanik serme istasyonunda homojen olarak pasta formu oluşturulmuştur. Oluşturulan pastalar önpresleme işlemi esnasında sıkıştırma işlemi yapılmıştır. Sıcak presleme esnasında 8 katlı pres $190^{\circ} \mathrm{C}$ ve $32-34$ $\mathrm{kg} / \mathrm{cm}^{2}$ ve $270 \mathrm{sn}$ içinde preslenerek levhalar oluşturulmuştur. Pres çıkışında soğutma işleminden sonra ebatlama işlemi yapılmıştır. Levhalar ara depoya alınarak 5 gün boyunca bekletilmiştir. Bekleme işleminden sonra levhaları alt ve üst yüzeyleri 40-80-120 kum zımpara bandı ile zımparalanmıştır. Kalsit katkılı levhalarda TS 642 ISO 554 standardına kondisyonlanmıştır. Kondisyonlanan levhalar ASTM E 160-50 standart deney parametrelerine göre kesim işlemi yapılmıştır. Kesim işlemi yapıldıktan sonra yanma deneyleri yapılmana kadar kondisyonlanmaya denge nem içeriği oluşana kadar devam edilmiştir.

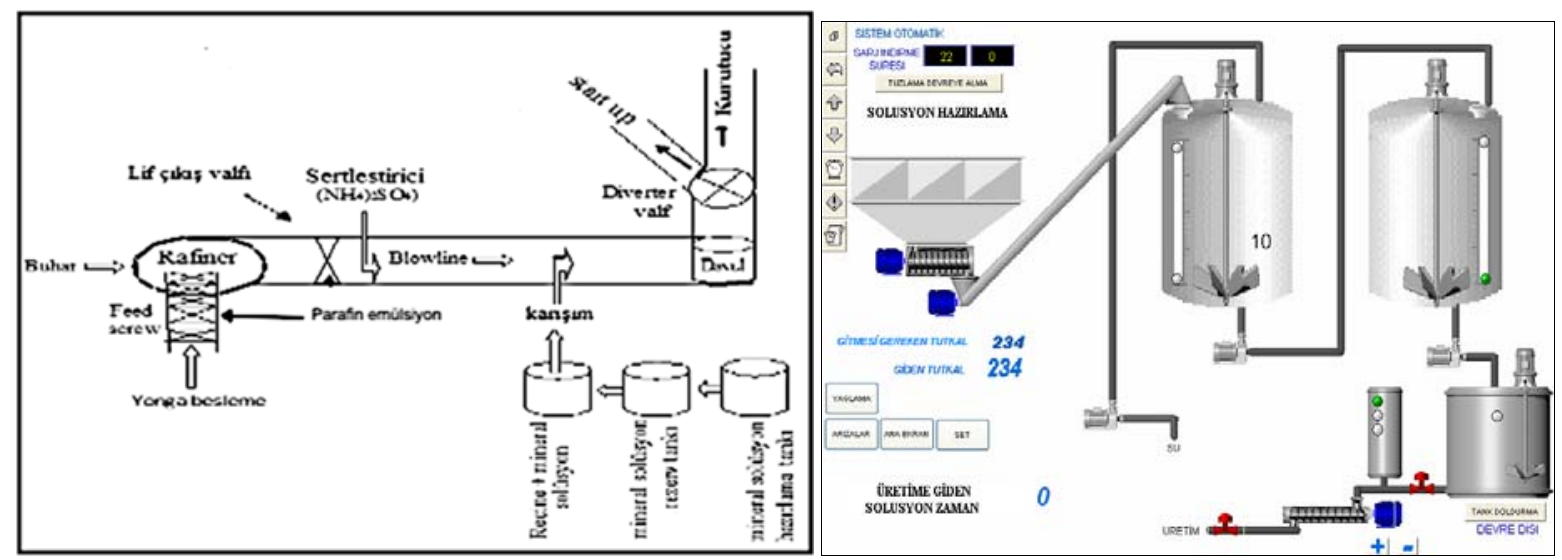

Şekil 1. Bağlayıcı (reçine+inorganik kalsit mineral) solüsyon ve diğer kimyasalların üretime verilmesi.

\section{3. Üretilen MDF'lerin testlerinin yapılması}

\subsubsection{Yanma testi yöntemi}

Her deney tipi için 13x13x76 mm (radyal x teğet x uzunluk) boyutlarında numuneler hazırlanmıştır. Kalsit MDF numunelerinin yanma testi ASTM E 160-50 (1976) 'ya göre belirlenmiştir [1]. MDF levhalarının spesifik özeliklerini TS 64-1 EN 622-1'e göre açıklanmıştır [18]. MDF levhaları deney yapılmadan önce TS 642 ISO 554 standardına göre kondisyonlanmıştır [19]. Numuneler $27 \pm 2{ }^{\circ} \mathrm{C}$ 'de ve $\% 30$ bağıl nemde, yanma testinden önce hedeflenen denge nem içeriği \%7 olacak şekilde koşullandırılmıştır.

Deneyler 12 katlı kare prizma şeklinde dizilerek yakılmıştır. Yakma işlemi boyunca, gaz basıncı standartta belirtildiği düzeyde sabit tutulmuştur.

Isıtma alevinin ateşi, hassas çubuk ölçülü bir valf tarafından kontrol edilen bir LPG tankından kaynaklanmıştır. Alev, yanma testi numunelerinin çerçevesinden önce standart yüksekliğe dengelendi. Yanma testi yöntemi daha sonra ASTM E 160-50'ye göre alev aşaması (FS), alevsiz aşama (WFS) ve kızdırma aşaması (GS) olarak gerçekleştirildi. Alev kademeli alev kademesiz ve kızdırma kademeli yanma için sırasıyla 15 ve 30 sn aralıklarla termokuplar kullanılarak yanma kolonundaki sıcaklıklar kaydedilmiştir. Kalsit katkılı MDF levhaların yanmaya karşı direnç etkinliği (ASTM E 160-50) aşağıdaki şekil 2'deki test yöntemi uygulanarak yanma direnci ölçülmektedir [1].

Kalsit katkılı MDF levhaların yanma özelliklerinin belirlenmesi amacıyla yapılan testler; alev kaynaklı yanma (AKY), kendi kendine yanma (KKY), kor halinde yanma (KHY), alev kaynaklı yanma lüks (AKY lüks), kendi kendine yanma lüks (KKY lüks), kor halinde yanma lüks (KHY lüks), kor halinde yanma zamanı (KHY zaman) ve yanma kaybı (ağırlık kaybı) aşamaları ölçülerek kaydedilmiştir. 
Kalsit katkılı levhaların yanma deneyinde 24'er adet 3'er parti olmak üzere 24x3=72 örnek yakılmıştır. Kontrol ve kalsit katkı1ı levhaların toplamı 12+1=13 gruptan oluşmaktadır. Toplamda 13x72=936 adet malzeme yakılmıştır. Yanma testinden sonra test numunelerinin kütle kaybı aşağıdaki denklem (1) ile hesaplanmıştır.

$$
\text { Kütle Kaybı }=\frac{(\text { Wbf-Waf })}{\text { Wbf }} \text { X } 100
$$

Bu deklemde; Wbf, yanma testinden önceki bir ahşap numunesinin ağırlığı (g) ve Waf, yanma testinden sonra bir ahşap numunesinin ağırlığıdır $(\mathrm{g})$.
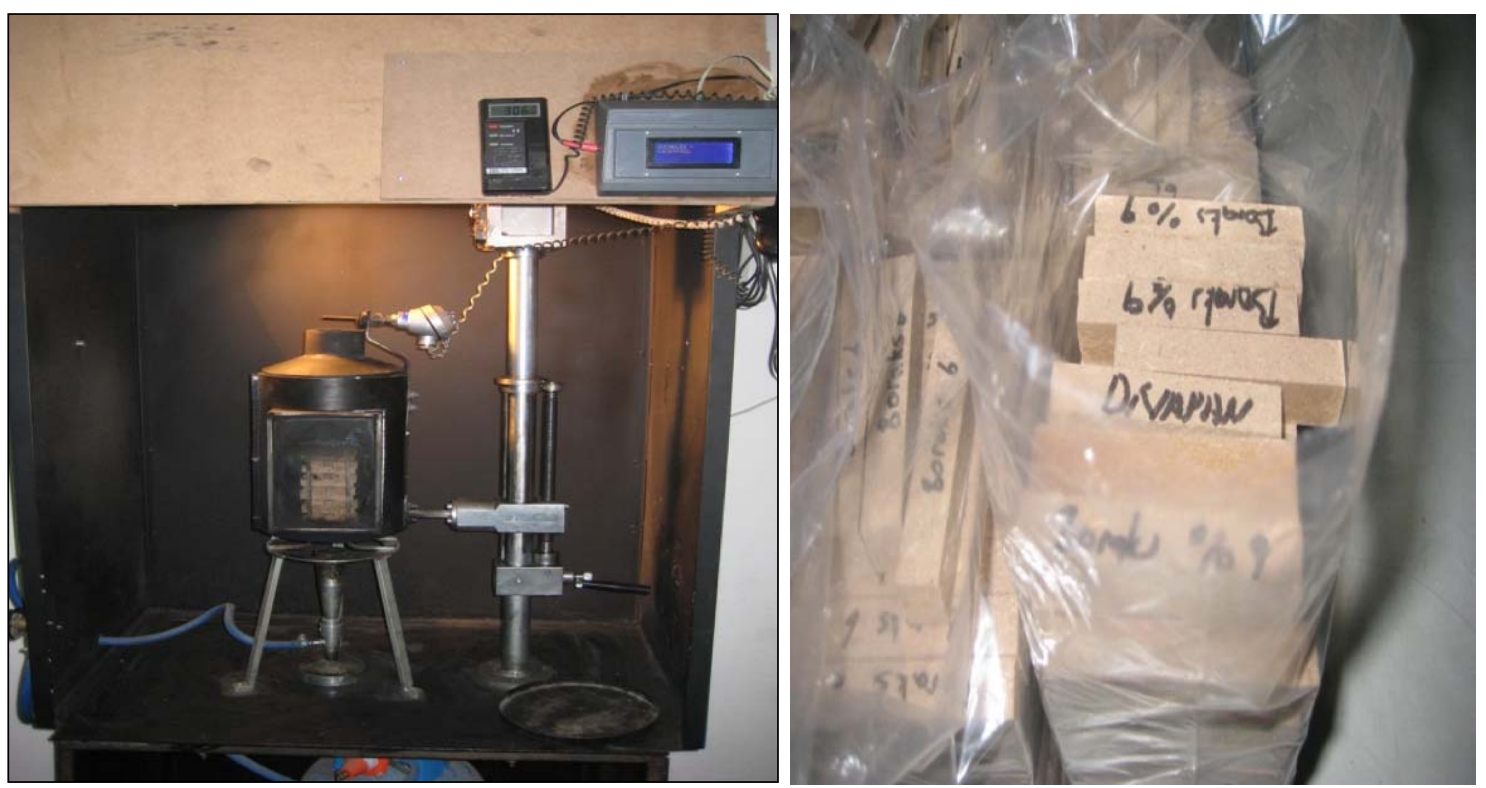

Şekil 2. Yanma deneyi düzeneği (sol) ve yanma malzemeleri (să̆).

Test sonuçları, SPSS-V22 bilgisayarlı bir istatistik paket programı kullanılarak \%95 güven aralığında ANOVA Duncan testleri ve varyans analizi ile istatitiksel olarak incelenmiştir.

\subsection{BULGULAR}

\subsection{MDF levhalarının yanma deneylerine ait bulgular}

Çizelge 2 üretim reçetesine bağlı kalarak üretilen orta yoğunlukta lif levhaların AKY, AKY lüks, KKY, KKY lüks, KHY, KHY lüks, KHY zaman ve Ağırlık kaybı testlerinin SPSS (ANOVA) Duncan sonuçları çizelge 3'te verilmiştir.

Çizelge 3. Kalsit katkılı levhaların yanma sonuçlarının istatistikî verileri

\begin{tabular}{|c|c|c|c|c|c|c|c|c|c|}
\hline \multirow{2}{*}{\multicolumn{2}{|c|}{$\begin{array}{l}\text { Levha } \\
\text { Kalsit }\end{array}$}} & \multirow[t]{2}{*}{$\mathrm{N}$} & \multirow[t]{2}{*}{ Ort. $^{x}$} & \multirow{2}{*}{$\begin{array}{c}\text { Std. } \\
\text { sapma }\end{array}$} & \multirow{2}{*}{$\begin{array}{c}\text { Std. } \\
\text { hata }\end{array}$} & \multicolumn{2}{|c|}{$95 \%$ Güven aralığ $1{ }^{*}$} & \multirow[t]{2}{*}{ Minumum } & \multirow[t]{2}{*}{ Maksimum } \\
\hline & & & & & & Alt sinir & Üst sinır & & \\
\hline \multirow{3}{*}{ 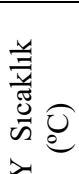 } & Kontrol & 72 & $560.21^{\mathrm{a}}$ & 17.97 & 12.71 & 398.71 & 721.70 & 547.50 & 572.92 \\
\hline & $\mathrm{R}_{97} \mathrm{C}_{3}$ & 72 & $551.16^{\mathrm{a}}$ & 12.36 & 8.74 & 440.10 & 662.21 & 542.42 & 559.90 \\
\hline & $\mathrm{R}_{94} \mathrm{C}_{6}$ & 72 & $545.12^{\mathrm{a}}$ & 0.53 & 0.37 & 540.36 & 549.89 & 544.75 & 545.50 \\
\hline 党 & $\mathrm{R}_{91} \mathrm{C}_{9}$ & 72 & $541.87^{a}$ & 29.28 & 20.70 & 278.79 & 804.95 & 521.17 & 562.58 \\
\hline \multirow{4}{*}{ 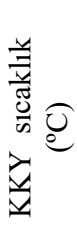 } & Kontrol & 72 & $662.57^{\mathrm{a}}$ & 6.64 & 4.69 & 602.91 & 722.23 & 657.88 & 667.27 \\
\hline & $\mathrm{R}_{97} \mathrm{C}_{3}$ & 72 & $652.31^{\mathrm{a}}$ & 16.87 & 11.93 & 500.72 & 803.89 & 640.38 & 664.24 \\
\hline & $\mathrm{R}_{94} \mathrm{C}_{6}$ & 72 & $624.66^{\mathrm{a}}$ & 33.37 & 23.60 & 324.79 & 924.52 & 601.06 & 648.26 \\
\hline & $\mathrm{R}_{91} \mathrm{C}_{9}$ & 72 & $609.56^{\mathrm{a}}$ & 18.08 & 12.78 & 447.11 & 772.01 & 596.78 & 622.35 \\
\hline
\end{tabular}




\begin{tabular}{|c|c|c|c|c|c|c|c|c|c|}
\hline \multirow{4}{*}{ 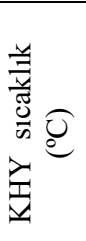 } & Kontrol & 72 & $652.57^{a}$ & 19.00 & 13.40 & 481.90 & 823.20 & 639.10 & 666.00 \\
\hline & $\mathrm{R}_{97} \mathrm{C}_{3}$ & 72 & $490.00^{b}$ & 14.10 & 10.00 & 362.90 & 617.10 & 480.00 & 500.00 \\
\hline & $\mathrm{R}_{94} \mathrm{C}_{6}$ & 72 & $480.50^{b}$ & 36.10 & 25.50 & 156.50 & 804.50 & 455.00 & 506.00 \\
\hline & $\mathrm{R}_{91} \mathrm{C}_{9}$ & 72 & $465.00^{b}$ & 35.40 & 25.00 & 147.30 & 782.70 & 440.00 & 490.00 \\
\hline \multirow{4}{*}{ 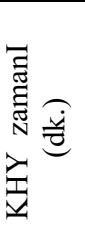 } & Kontrol & 72 & $64.33^{a}$ & 0.94 & 0.67 & 55.81 & 72.83 & 63.60 & 65.00 \\
\hline & $\mathrm{R}_{97} \mathrm{C}_{3}$ & 72 & $73.00^{b}$ & 1.41 & 1.00 & 60.29 & 85.70 & 72.00 & 74.00 \\
\hline & $\mathrm{R}_{94} \mathrm{C}_{6}$ & 72 & $69.75^{b}$ & 2.12 & 1.50 & 50.69 & 88.80 & 68.25 & 71.25 \\
\hline & $\mathrm{R}_{91} \mathrm{C}_{9}$ & 72 & $65.25^{\mathrm{a}}$ & 2.47 & 1.75 & 43.01 & 87.48 & 63.50 & 67.00 \\
\hline \multirow{4}{*}{ 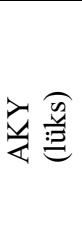 } & Kontrol & 72 & $309.00^{\mathrm{a}}$ & 2.82 & 2.00 & 283.58 & 334.41 & 307.00 & 311.00 \\
\hline & $\mathrm{R}_{97} \mathrm{C}_{3}$ & 72 & $254.40^{b}$ & 2.68 & 1.90 & 230.25 & 278.54 & 252.50 & 256.30 \\
\hline & $\mathrm{R}_{94} \mathrm{C}_{6}$ & 72 & $269.71^{b c}$ & 4.18 & 2.96 & 232.10 & 307.32 & 266.75 & 272.67 \\
\hline & $\mathrm{R}_{91} \mathrm{C}_{9}$ & 72 & $276.08^{c}$ & 10.48 & 7.41 & 181.86 & 370.30 & 268.67 & 283.50 \\
\hline \multirow{4}{*}{$\underset{v}{\underline{\Delta}}$} & Kontrol & 72 & $302.42^{\mathrm{a}}$ & 24.86 & 17.58 & 79.04 & 525.79 & 284.84 & 320.00 \\
\hline & $\mathrm{R}_{97} \mathrm{C}_{3}$ & 72 & $266.81^{a}$ & 3.26 & 2.31 & 237.45 & 296.16 & 264.50 & 269.12 \\
\hline & $\mathrm{R}_{94} \mathrm{C}_{6}$ & 72 & $274.31^{\mathrm{a}}$ & 8.49 & 6.00 & 198.01 & 350.61 & 268.31 & 280.32 \\
\hline & $\mathrm{R}_{91} \mathrm{C}_{9}$ & 72 & $284.71^{\mathrm{a}}$ & 7.24 & 5.12 & 219.65 & 349.76 & 279.59 & 289.83 \\
\hline \multirow{4}{*}{ 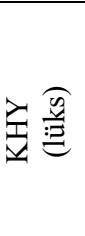 } & Kontrol & 72 & $302.57^{\mathrm{a}}$ & 19.19 & 13.57 & 130.14 & 474.99 & 289.00 & 316.14 \\
\hline & $\mathrm{R}_{97} \mathrm{C}_{3}$ & 72 & $271.00^{\mathrm{a}}$ & 8.48 & 6.00 & 194.76 & 347.23 & 265.00 & 277.00 \\
\hline & $\mathrm{R}_{94} \mathrm{C}_{6}$ & 72 & $276.21^{\mathrm{a}}$ & 8.78 & 6.21 & 197.246- & 355.18 & 270.00 & 282.43 \\
\hline & $\mathrm{R}_{91} \mathrm{C}_{9}$ & 72 & $283.50^{\mathrm{a}}$ & 10.60 & 7.50 & 188.20 & 378.79 & 276.00 & 291.00 \\
\hline \multirow{4}{*}{ 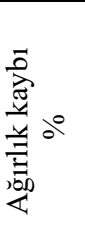 } & Kontrol & 72 & $96.35^{\mathrm{a}}$ & 0.07 & 0.05 & 95.71 & 96.98 & 96.30 & 96.40 \\
\hline & $\mathrm{R}_{97} \mathrm{C}_{3}$ & 72 & $95.60^{\mathrm{a}}$ & 0.14 & 0.10 & 94.32 & 96.87 & 95.50 & 95.70 \\
\hline & $\mathrm{R}_{94} \mathrm{C}_{6}$ & 72 & $94.10^{b}$ & 0.42 & 0.30 & 90.28 & 97.91 & 93.80 & 94.40 \\
\hline & $\mathrm{R}_{91} \mathrm{C}_{9}$ & 72 & $93.25^{\mathrm{c}}$ & 0.35 & 0.25 & 90.07 & 96.42 & 93.00 & 93.50 \\
\hline
\end{tabular}

N: Örnek sayısı. * 95\% güven aralığı ortalama için ANOVA. a,b,c aynı harf olan değerler anlamlı olarak farklı değildir (Duncan's test).

Bu yanma testi esnasında ölçümlen değerler; AKY (sıcaklık ve lüks), KKY (sıcaklık ve lüks), KHY (sıcaklık ve lüks), KHY lüks, İYB (sıcaklık, zamanı ve lüks), TY (sıcaklık, zamanı ve lüks), KHYS (dakika) ve Ağırlık kaybı verileri çizelge 4'da gösterilmiştir.

Çizelge 4. Kalsit katkılı levhaların yanma esnasında yanma ölçüm değerleri

\begin{tabular}{|c|c|c|c|c|c|c|c|c|c|c|c|c|c|c|}
\hline \multicolumn{15}{|c|}{ MDF levhaların yanma test sonuçları } \\
\hline \multirow{2}{*}{$\begin{array}{l}\text { MDF } \\
\text { levha }\end{array}$} & \multicolumn{2}{|c|}{ AKY ORT. } & \multicolumn{2}{|c|}{ KKY ORT. } & \multicolumn{2}{|c|}{ KHY ORT } & \multicolumn{3}{|c|}{ İYB ORT } & \multicolumn{3}{|c|}{ TY } & \multirow{2}{*}{$\begin{array}{c}\text { KHYS } \\
\text { dakika } \\
\text { (dk) }\end{array}$} & \multirow{2}{*}{$\begin{array}{c}\text { A ğırlık } \\
\text { kaybı } \\
(\%)\end{array}$} \\
\hline & $\begin{array}{c}\text { s1caklik } \\
\left({ }^{\circ} \mathrm{C}\right)\end{array}$ & (lüks) & $\begin{array}{c}\text { s1caklik } \\
\left({ }^{\circ} \mathrm{C}\right)\end{array}$ & (lüks) & $\begin{array}{c}\text { sicaklik } \\
\left({ }^{\circ} \mathrm{C}\right)\end{array}$ & (lüks) & $\begin{array}{c}\text { s1caklik } \\
\left({ }^{\circ} \mathrm{C}\right)\end{array}$ & $\begin{array}{c}\text { zaman } \\
(\mathrm{sn})\end{array}$ & (lüks) & $\begin{array}{c}\text { s1caklik } \\
\left({ }^{\circ} \mathrm{C}\right)\end{array}$ & $\begin{array}{c}\text { zaman } \\
(\mathrm{sn})\end{array}$ & (lüks) & & \\
\hline Kontrol & 560.21 & 309.00 & 662.58 & 302.42 & 652.57 & 302.57 & 654 & 150 & 321.00 & 614.00 & 540 & 301.00 & 64.33 & 96.40 \\
\hline $\mathrm{R}_{97} \mathrm{C}_{3}$ & 551.17 & 254.42 & 652.31 & 266.81 & 490.00 & 271.00 & 700 & 270 & 268.00 & 490.00 & 525 & 271.00 & 73.00 & 95.60 \\
\hline $\mathrm{R}_{94} \mathrm{C}_{6}$ & 545.13 & 269.71 & 624.66 & 274.31 & 480.50 & 276.21 & 618 & 240 & 277.50 & 457.50 & 645 & 276.50 & 69.75 & 94.10 \\
\hline $\mathrm{R}_{91} \mathrm{C}_{9}$ & 541.88 & 276.08 & 609.57 & 284.71 & 465.00 & 283.50 & 586 & 180 & 284.50 & 450.00 & 630 & 283.50 & 65.25 & 93.30 \\
\hline
\end{tabular}

\section{TARTIŞMA VE SONUÇLAR}

Çizelge3'e göre kalsit katkılı levhaların kendi arasında istatistiksel bir anlamlı farklılık bulunmamaktadır. Kontrol levhasının AKY sıcaklıkları $\left(560.21{ }^{\circ} \mathrm{C}\right)$ ölçülmüştür. $\mathrm{R}_{97} \mathrm{C}_{3}$ levhasının $\left(551.16^{\circ} \mathrm{C}\right) \mathrm{AKY}$ sıcaklığı ölçülmüştür. $\mathrm{R}_{97} \mathrm{C}_{3}$ levhası kontrol levhasına göre \%1.64 AKY sıcaklığı azalmaktadır. $\mathrm{R}_{94} \mathrm{C}_{6}$ levhasının $\left(545.12{ }^{\circ} \mathrm{C}\right) \mathrm{AKY}$ 
sıcaklığı ölçülmüştür. $\mathrm{R}_{94} \mathrm{C}_{6}$ levhası kontrol levhasına göre \%1.76 AKY sıcaklığı azalmaktadır. $\mathrm{R}_{91} \mathrm{C}_{9}\left(541.87{ }^{\circ} \mathrm{C}\right)$ AKY sıcaklığ1 ölçülmüştür. $\mathrm{R}_{91} \mathrm{C}_{9}$ levhası kontrol levhasına göre \%3.38 AKY sıcaklığı azalmakta ve levhanın yanmaya karşı dirençli olduğu tespit edilmiştir. Orta yoğunlukta lif levhalarında inorganik mineral miktarı arttıkça AKY sıcaklığı azalmaktadır. Bundan dolayı MDF üretiminde kullanılan Kalsit inorganik minarelerin bünyelerinde 1sıyı absorbe ettiği ve yanmaya karşı dirençli olduğu görülmektedir. Orta yoğunlukta lif levhaların yanmaya karşı direnç göstermesinin inorganik minerallerin kimyasal yapısından kaynaklanmaktadır. KKY sıcaklığının SSPS sonuçları çizelge 3'te gösterilmektedir. İstatistiki analizlere göre kalsit katkılı levhalar arasında anlamlı farklılık bulunmamaktadır. Kontrol levhasının KKY sıcaklığı Kontrol $\left(662.57{ }^{\circ} \mathrm{C}\right)$ ölçülmüştür. $\mathrm{R}_{97} \mathrm{C}_{3}$ levhas $1\left(652.31{ }^{\circ} \mathrm{C}\right)$ KKY sıcaklığı ölçülmüş ve kontrol levhasına göre \%1.57 KKY sicaklığ1 yanmaya karşı direnç göstermektedir. Kontrol $\left(624.66{ }^{\circ} \mathrm{C}\right) \mathrm{KKY}$ sicaklığ 1 ölçülmüştür. $\mathrm{R}_{94} \mathrm{C}_{6}$ levhası kontrol levhasına göre \%6.06 KKY sicaklığ yanmaya karşı direnç göstermektedir. $\mathrm{R}_{91} \mathrm{C}_{9}\left(609.56{ }^{\circ} \mathrm{C}\right) \mathrm{KKY}$ sıcaklığı ölçülmüştür. $\mathrm{R}_{91} \mathrm{C}_{9}$ levhası kontrol levhasına göre \%8.69 KKY sıcaklığı levhada yanmaya karşı dirençlidir. KKY sicaklığ 1 test sonucu $\mathrm{R}_{97} \mathrm{C}_{3}(652.31$ $\left.{ }^{\circ} \mathrm{C}\right), \mathrm{R}_{94} \mathrm{C}_{6}\left(624.66^{\circ} \mathrm{C}\right), \mathrm{R}_{91} \mathrm{C}_{9}\left(609.56^{\circ} \mathrm{C}\right), \mathrm{KKY}$ belirtilmektedir. KKY sıcaklık değerinin düşmesi Kalsit inorganik minarelerinin kimyasal özelliklerinden kaynaklanmaktadır.

KHY sıcaklığının SSPS sonuçları çizelge 3'te gösterilmektedir. Bu istatistiki analizlere göre; kalsit katkılı levhalar $\left(\mathrm{R}_{97} \mathrm{C}_{3}, \mathrm{R}_{94} \mathrm{C}_{6}, \mathrm{R}_{91} \mathrm{C}_{9}\right)$ ve kontrol numuneleri arasında anlamlı farklılık bulunmaktadır. KHY sıcaklığı testi sonucu sırasıyla kontrol levhası için $652.57^{\circ} \mathrm{C}, \mathrm{R}_{97} \mathrm{C}_{3}$ için $490.00{ }^{\circ} \mathrm{C}, \mathrm{R}_{94} \mathrm{C}_{6}$ için $480.50{ }^{\circ} \mathrm{C}, \mathrm{R}_{91} \mathrm{C}_{9}$ için $465.00{ }^{\circ} \mathrm{C}$ olarak test edilmiştir. $\mathrm{R}_{97} \mathrm{C}_{3}$ levhası kontrol levhasına göre $\mathrm{KHY}$ sıcaklığı \%33.17 azaldığ gözlemlenmiştir.

$\mathrm{R}_{94} \mathrm{C}_{6}$ levhasının KHY sıcaklığı kontrol levhasına göre \%35.81 KHY sıcaklığ 1 azalmaktadır. $\mathrm{R}_{91} \mathrm{C}_{9}$ levhası KHY sıcaklığ1 kontrol levhasına göre \%40.33 yanma karşı direnç göstermiştir.

KHY zaman SPSS sonuçları çizelge 3'te gösterilmiştir. Sonuçlara göre bu değer için gruplar arasında istatiksel olarak anlamlı farklılık gözlemlenmiştir. Kontrol levhasının KHY zaman 64.33 dakikadır. $\mathrm{R}_{97} \mathrm{C}_{3}$ levhasının $\mathrm{KHY}$ zamanı $73 \mathrm{dk}$ ölçülmüştür. $\mathrm{R}_{97} \mathrm{C}_{3}$ levhası kontrol levhasına göre \%13.47 KHY zamanı artmaktadır. $\mathrm{R}_{94} \mathrm{C}_{6}$ levhası $\mathrm{KHY}$ zamanı $69.75 \mathrm{dk}$ ölçülmüştür. $\mathrm{R}_{94} \mathrm{C}_{6}$ levhası kontrol levhasına göre \%8.42 KHY zamanı artmaktadır. $\mathrm{R}_{91} \mathrm{C}_{9}$ levhası KHY zamanı 65.25 dk ölçülmüştür. $\mathrm{R}_{91} \mathrm{C}_{9}$ levhası kontrol levhasına göre \%1.40 KHY zamanı artmaktadır. Kalsit inorganik miktarı artıkça MDF yanma süresini uzatmaktadır.

AKY 1şı yoğunluğu (lüks) SPSS sonuçları çizelge 3'te gösterilmektedir. AKY 1ş1k yoğunluğu; kontrol, $\mathrm{R}_{97} \mathrm{C}_{3}$ ve $\mathrm{R}_{94} \mathrm{C}_{6}, \mathrm{R}_{94} \mathrm{C}_{6}$ ve $\mathrm{R}_{91} \mathrm{C}_{9}$, arasında istatistiksel olarak anlamlı farklılık bulunmaktadır. AKY lüks deney sonuçları sırasıyla kontrol (309.00 lüks), $\mathrm{R}_{97} \mathrm{C}_{3}$ (254.40 lüks), $\mathrm{R}_{94} \mathrm{C}_{6}$ (269.71 lüks), $\mathrm{R}_{91} \mathrm{C}_{9}$ (276.08 lüks) şeklinde bulunmuştur. $\mathrm{R}_{97} \mathrm{C}_{3}$ levhası kontrol levhasına göre \%21.46 AKY lüks azalmaktadır. $\mathrm{R}_{94} \mathrm{C}_{6}$ levhası kontrol levhasına göre \%14.56 AKY 1şık yoğunluğu azalmaktadır. $\mathrm{R}_{91} \mathrm{C}_{9}$ levhası kontrol levhasına göre \%11.92 AKY lüx azalmaktadır. Orta yoğunlukta lif levhalarında kalsit inorganik dolgu miktarı arttıkça AKY 1şık yoğunluğu azalmakta ve koyu duman çıkmaktadır. Böylece ışık yoğunluğu azalmaktadır.

KKY lüks değerinin SPSS sonuçları çizelge 3'te gösterilmektedir. Bu istatistiki analizlere göre; kalsit katkılı levhalar arasında anlamlı farklılık bulunmamaktadır. Kontrol levhasının 302.42 lüks KKY 1şık yoğunluğu ölçülmüştür. $\mathrm{R}_{97} \mathrm{C}_{3}$ levhasının 266.81 lüx KKY lüx ölçülmüştür. $\mathrm{R}_{97} \mathrm{C}_{3}$ levhası kontrol levhasına göre \%13.34 KKY lüks azalmaktadır. $\mathrm{R}_{94} \mathrm{C}_{6}$ levhası $\mathrm{KKY}$ lüks değeri 274.31 lüks ölçülmüştür. $\mathrm{R}_{94} \mathrm{C}_{6}$ levhası kontrol levhasına göre \%10.24 KKY lüks değeri azalmaktadır. $\mathrm{R}_{91} \mathrm{C}_{9}$ levhası KKY lüks 284.31 lüks değeri ölçülmüştür. $\mathrm{R}_{91} \mathrm{C}_{9}$ levhas1 kontrol levhasına göre \%6.36 KKY lüks değeri azalmaktadır. Sonuçlara göre kalsit katkılı MDF kendi kendine yanarken koyu duman azalmaktadır ve ışık yoğunluğu artmakta olduğu anlaşılmaktadır.

KHY lüks değerinin SPSS sonuçları çizelge 3'te gösterilmektedir. Bu istatistiki analizlere göre; kalsit katkılı levhalar arasında anlamlı farklılık bulunmamaktadır. Kontrol levhasının (302.57 lüks) KHY 1şık yoğunluğu ölçülmüştür. $\mathrm{R}_{97} \mathrm{C}_{3}$ levhasının $\mathrm{KHY}$ 1şık yoğunluğu 271.00 lüks ölçülmüş ve kontrol levhasına göre \%11.64 KHY lüks azalmaktadır. $\mathrm{R}_{94} \mathrm{C}_{6}$ levhasının $\mathrm{KHY}$ 1şık yoğunluğu 276.21 lüks ölçülmüştür. $\mathrm{R}_{94} \mathrm{C}_{6}$ levhası kontrol levhasına göre \%9.54 KHY lüks azalmaktadır. $\mathrm{R}_{91} \mathrm{C}_{9}$ levhasının $\mathrm{KHY}$ (283.50 lüks) 1şık yoğunluğu ölçülmüştür. $\mathrm{R}_{91} \mathrm{C}_{9}$ levhası kontrol levhasına göre \%6.72 KHY lüks değeri azalmaktadır. Sonuç olarak kalsit miktarı arttıkça KHY 1şık yoğunluğu azalmaktadır. Dolayısıyla yanma esnasında koyu duman az miktarda oluştuğu belirlenmiştir.

A ğırlık kaybı SPSS sonuçları çizelge 3'te gösterilmektedir. İstatistiki analize göre kalsit katkılı levhalar kontrol ve $\mathrm{R}_{97} \mathrm{C}_{3}, \mathrm{R}_{94} \mathrm{C}_{6}, \mathrm{R}_{91} \mathrm{C}_{9}$ arasında istatiksel olarak anlamlı bir farklılık bulunmaktadır. Kontrol levhasının ağırlık kaybı \%96.35 ölçülmüştür. $\mathrm{R}_{97} \mathrm{C}_{3}$ levhasının \%95.60 ağırlık kaybı ölçülmüş ve kontrol levhasına göre \%0.78 ağırlık kaybı azalmaktadır. $\mathrm{R}_{94} \mathrm{C}_{6}$ levhası \%94.10 ağırlık kaybı ölçülmüştür. $\mathrm{R}_{94} \mathrm{C}_{6}$ levhası kontrol levhasına göre \%2.39 ağırlık kaybı azalmaktadır. $\mathrm{R}_{91} \mathrm{C}_{9}$ levhası \%93.25 ağırlık kaybı ölçülmüştür. $\mathrm{R}_{91} \mathrm{C}_{9}$ levhası kontrol levhasına göre \%3.37 ağırlık kaybı ölçülmüştür. Sonuçlara göre kalsit katkı miktarı arttıkça yanma sonucu kül miktarı artmaktadır.

Çizelge 4'te kalsit katkılı levhaların yanma test performanslarına ait İYB (sıcaklık, zaman, lüks), TY (zaman, lüks), KHYS (dk) değerleri verilmiştir. Bu test sonuçlarına göre; MDF levha içinde kalsit miktarı artıkça TS (dk) arttığı görülmektir. Fakat KHYS (dk) azaldığı ölçülmüştür. Kalsit miktarı \%9 olan MDF levhalarının IYYB sıcaklık süresinin uzadığı ve levhaların tutuşma süresi arttığı görülmektedir.

MDF üretiminde kalsit mineralleri kullanım üzerine yapılan bir çalışmada, üretimde kalsit mineralinin yüzdesi arttıkça fiziksel ve mekanik özellikler üzerinde olumsuz etki ettiğini ve MDF levha üretimi için kalsit mineralleri kullanım oranları (\%3 ve \%6) olması yönünde önerilerde bulunmuştur [10].

Laboratuvar ölçekli çalışmada, sırasıyla \%10, \%20 ve \%30 oranlarında liflerin yerine kalsit ağırlık bazında (kuru/kuru) ve üç farklı hedef yoğunluğunda (550, 700 ve $850 \mathrm{~kg} / \mathrm{m}^{3}$ ) MDF levhalarının üretimini 
gerçekleştirmiştir. Araştırma sonuçlara göre, ağırlıkça \%10'a kadar olan MDF levhalara mineral dolgu ilavesi, lif levhaların özellikleri üzerinde, eğer hiç değilse, sadece küçük bir etkiye sahip olduğunu ve kalsitin reçinenin kürlenmesinde mukavemet gelişimi ve kalınlık şişmesi üzerinde herhangi bir etkisi olmadığını ifade etmişlerdir [16].

Özetle; bu çalışma ile MDF üretiminde, kalsit mineralinin yangına karşı direnç sağlayıcı alternatif inorganik mineral olarak kullanılabileceği sonucuna varılmıştır.

\section{5. ÖNERILER}

Deneylerde, kalsit mineral miktarı arttıkça yanmaya karşı direnci artmaktadır. Özellikle \%9 kalsit katkılı levhaların AKY sıcaklığında \%3.38, KKY sıcaklığında \%8.69 ve KHY sıcaklığında \%40.33 oranında yanmaya karşı direnç göstermektedir. Kalsit katkılı MDF levhalarının yanma test sonuçlarına göre, kalsit minerali MDF üretimine yangına karşı direnç oluşturmasından dolayı üretimde uygun olduğu görülmüştür. Kalsit MDF üretiminde yangın geciktirici olarak değerlendirilmesi mümkündür. MDF üretiminde ülkemizin yeraltı zenginliklerinden kalsit mineralleri yangına karşı direnç sağlayıcı kimyasallara karşı alternatif kaynak olarak kullanılabileceği bu çalışma ile ortaya koyulmuştur. Kalsit katkılı MDF levhaları özellikle yangın riski çok fazla olan iç mekân mutfak mobilyalarının imalatında kullanılması mümkündür.

\section{Yazar Katkıları}

Yazarlar çalışmaya eşit oranlı katkı sunmuşlardır.

\section{Çıkar Çatışması}

Makale yazarları aralarında herhangi bir çıkar çatışması olmadığını beyan ederler

\section{Teşekkür}

Bu çalışma Bilim Sanayi ve Teknoloji Bakanlığı tarafından San-Tez 00653.STZ.2010-2 olarak desteklenmiştir. T.C. Düzce Üniversitesi Orman Fakültesi, T.C. Gazi Üniversitesi Ağaç İşleri Endüstri Mühendisliği ve Divapan Entegre AŞ firmasının katkılarından dolayı teşekkür ederiz.

\section{KAYNAKÇA}

[1] ASTM E 160-50, Standard test method for combustible properties of treated wood by the crib test, 1976.

[2] A. İstek, D. Aydemir, H. Eroğlu, “Combustion properties of medium-density fiberboards coated by a mixture of calcite and various fire retardants" Turkish Journal of Agriculture and Forestry 37: 642-648 (C) TÜBİTAK, 2013.

[3] A. Dönmez Çavdar, S. Boran Torun, M. Ertas ve F. Mengeloglu, "Ammonium zeolite and ammonium phosphate applied as fire retardants for microcrystalline cellulose filled thermoplastic composites," Fire Safety Journal 107, 202-209. DOI: 10.1016/j.firesaf.2018.11.008, 2019.

[4] A. Ozcıfcı, H. Toker, E. Baysal, "Fire properties of laminated veneer lumber treated with some fire retardants" Wood Research 52(4): pages: 37-46, 2007.

[5] A.P.S. Silva, B.S. Ferreira, H.R. Favarim, M.F.F. Silva, J.V.F. Silva, M.A. Azambuja and C.I. Campos, "Physical properties of medium density fiberboard produced with the addition of $\mathrm{ZnO}$ nanoparticles," BioResources 14(1), 1618-1625. DOI: 10.15376/Biores.14.1.1618-1625, 2019.
[6] M. Usta ve D. Ustaömer, "Boron compounds for MDF’, BioResources, 7(1), 437-446, (2012).

[7] Faostat, "Forestry Production and Trade. Food and Agriculture Organization of the United Nations", http://www.fao.org/faostat/en/\#data/FO, Accessed: 24.01.2020.

[8] G.Tondi, L. Haurie, S.Wieland, "Comparison of disodium octaborate tetrahydrate-based and tannin-boron-based formulations as fire retardant for wood structures," Fire and Materials 38(3), 381-390, 2014.

[9] H. Hafizoglu, M.K. Yalinkilic, U.C. Yildiz, E. Baysal, H. Peker, Z. Demirci, "Utilization of Turkey's Boron Reserves in Wood Preservation Industry" Project of Turkish Science and Tech. Council (TUBITAK), Code: TOAG-875, 377 pp (in Turkish), 1994.

[10] H. Kalaycıŏ̆lu, H.Yel, A. Dönmez ,Çavdar, "Wood wool cement boards and its applications" Kastamonu University Journal of Forestry Faculty 12 (1): 122-133, 2012.

[11] H.R. Taghiyari, M.P. Behrooz, J.J. Morrell, “ Effects of wollastonite on the properties of medium-density fiberboard (MDF) made from wood fibers and camel-thorn" Maderas. Ciencia Y Tecnología 18(1), 157 - 166, 2016.

[12] J. Wang, F. Wang, Z. Gao, M. Zheng and J. Sun, $\mathrm{J}$, "Flame retardant medium-density fiberboard 
with expanded vermiculite', Bioresources 11(3): 6940-6947, 2016.

[13] M. Akgül, B. Uner, O. Çamlibel, U. Ayata, "Manufacture of Medium Density Fiberboard (MDF) Panels From Agribased Lignocellulosic B1omass". Wood Research 62 (4), 615-624, 2017.

[14] O. Camlibel, ve M. Akgul, "Mechanical and physical properties of medium density fibreboard with calcite additive," Wood Research 65 (2), 231-244, 2020.

[15] S. LeVan, H.C. Tran, "The role of boron in flame retardant treatments. In: Proceedings of first international conference on wood protection with diffusible preservatives" First International Conference on Wood Protection with Diffusible Preservatives: Nashville, Tennessee, November 28-30, 1990. Madison, WI: Forest Products Research Society, pp.39-41:ill.Publication Series: Miscellaneous Publication, 1990.

[16] T. Ozyhar, T. Depnering, C. Ridgway, M. Welker, I. Schoelkopf., Mayer and H. Thoemen, "Utilization of inorganic mineral filler material as partial replacement for wood fiber in medium density fiberboard (MDF) and its effect on material properties," European Journal of Wood and Wood Products 78(1), 75-84. DOI: 10.1007/s00107-019-01480-1,2020.

[17] Y. Zuo, J. Xiao, J. Wang, W. Liu, X. Li, and Y. $\mathrm{Wu}$, "Preparation and characterization of fire retardant straw/magnesium cement composites with an organic-inorganic network structure' . Construction and Building Materials. Vol.171 pp. 404-413, 2018.

[18] TS 64-1 EN 622-1, “Lif levhalar özelliklerbölüm 1: genel özellikler’, TSE, Ankara, 2005.

[19] TS 642-ISO 554, “Kondisyonlama ve/veya deney için standart atmosfer - özellikler’’, TSE, Ankara, 1997

[20] O. Çamlıbel ve M. Akgül, “The Utilizing Rock Salt of Inorganic Filler in Medium Density Fibreboard (MDF) Production,' Kastamonu University., Journal of Forestry Faculty, 20(2); 158-174, Doi: 10.17474/kastorman.801814, 2020 